\title{
Impacts of alien invasive Parthenium hysterophorus on flower visitation by insects to co-flowering plants
}

\author{
Fredrick Ojija ${ }^{1,2}$, Sarah E.J. Arnold ${ }^{3}$, Anna C. Treydte ${ }^{1,4}$ \\ ${ }^{1}$ Department of Sustainable Agriculture, Biodiversity and Ecosystem Management, School of Life Sciences and Bio- \\ Engineering, The Nelson Mandela African Institution of Science and Technology, P.O. Box 447, Arusha, Tanzania \\ ${ }^{2}$ Institute of Science and Technology, Mbeya University of Science and Technology, P.O. Box 131, Mbeya, Tanzania \\ ${ }^{3}$ Natural Resources Institute, University of Greenwich, Chatham Maritime ME4 4TB, UK \\ ${ }^{4}$ Hans Ruthenberg Institute, Agroecology in the Tropics and Subtropics, University of Hohenheim, Garbenstr. 13, 70599 \\ Stuttgart, Germany
}

\begin{abstract}
The exotic invasive plant Parthenium hysterophorus is invading many tropical habitats. While much work has been done on its interactions with other native plants, little is known about its interaction with insect floral visitors and how it impacts pre-existing pollination networks when it invades a site. We carried out surveys on sites with and without $P$. hysterophorus (invaded and uninvaded, respectively) to investigate its impact on plant-pollinator interactions with two common indicator or target plants (O. gratissimum and A. conyzoides) in Tanzania. During multiple 15 minute observation periods in quadrats, the number of arriving flower visitors, duration of visits and visitation rate were measured and compared between sites. Visitation networks of flower visitors were developed by observing flower visitor taxonomic groups and plants visited across both invasion categories. Parthenium hysterophorus was heavily visited by a diversity of flies as taxonomic groups. Indicator plants received fewer flower visitors overall in the invaded site, implying $P$. hysterophorus may be disrupting pollen flow. Foraging behaviour and flower visitation by Apis mellifera and flies on target plants were particularly negatively affected in the invaded quadrats. Flower visitation rate to target plants was significantly lower in invaded quadrats than in uninvaded quadrats. This study supports work in other parts of the world demonstrating that invasive species can strongly disrupt pollination networks. By attracting flower visitors that could otherwise serve as pollinators of native plant species, $P$. hysterophorus which is rapidly spreading in eastern African ecosystems could have complex deleterious effects on the wider ecosystem.
\end{abstract}

Keywords Biodiversity, Exotic species, Insects, Pollinators, Africa, Tanzania

\section{Introduction}

Pollination services are important in maintaining plant diversity and consequently biodiversity conservation (Bjerknes et al. 2007; Martins 2014). In flowering plants, pollination is a vital process that contributes to production of fruits and seeds (Lázaro et al. 2013; Martins 2014; Barrios et al. 2016; Weissman and Schaefer 2017). It occurs when flower visitors (pollinators) transfer pollen from the male part of a flower (anthers) to the female part (stigmas) of the same or another flower which results into fertilization (Albano et al. 2009; Flanagan et al. 2009; Lázaro et al. 2013). Almost 90\% of flowering plants rely on insects for pollination (Engel and Irwin 2003). Many plants are obligate insect-pollinated and will not set seed without pollinator visits. Although pollination is an important process for ecological functioning, it has often been ignored when studying the impact of introduced invasive plant species on biodiversity (Bjerknes et al. 2007; Stiers et al. 2014). Previously, studies 
have shown that introduce plants affect pollination and reproductive success of native plants (Brown et al. 2002; Morales and Traveset 2008; Flanagan et al. 2009; Emer et al. 2015). However, the effect varies with plant species (Larson et al. 2006; Bjerknes et al. 2007), season and site where invasion has occurred as well as the magnitude and time of invasion (Emer et al., 2015). Not all introduced plants have negative effects on biodiversity and pollination but rather have neutral or positive effects (Bartomeus et al. 2008; Molina-Montenegro et al. 2008; Albano et al. 2009; Traveset and Richardson 2014; Ye et al. 2014). Introduced invasive plants with positive effects tend to facilitate visitation of flower visitors to native flowering plants, while those with negative effect compete for flower visitors with native plants (Moragues and Traveset 2005; Morales and Traveset 2008). Furthermore, introduced plants with negative effects may outcompete native flowering plants (Larson et al. 2006; Nielsen et al. 2008) and alter ecological processes such as changes in composition of native plants (decreasing species richness and population size) in the invaded habitats (Emer et al. 2015). While sharing of flower visitors is common in a plant community (Aizen et al., 2008; Bjerknes et al., 2007; Emer et al., 2015; Lopezaraiza-Mikel et al., 2007; Morales and Traveset, 2008), competition for flower visitation due to sharing of flower visitors between introduced and native plants (McKinney and Goodell 2011; Ye et al. 2014) can affect pollination of native flowering plants by reducing visits to co-flowering plants (Aizen et al. 2008).

Some introduced plants are described as magnet species because they attract flower visitors (Molina-Montenegro et al. 2008; Nielsen et al. 2008; Gibson et al. 2013) due to their numerous attractive or colourful flowers (Brown et al. 2002; Nielsen et al. 2008) with greater amounts of pollen and nectar (Morales and Traveset 2008; Emer et al. 2015). They also form large monospecific patches with abundant flowers (Traveset and Richardson 2014), which makes them outcompete native flowering plants as a result of insufficient visits (Larson et al. 2006; Albano et al. 2009). This reduces reproductive success and seed set in native plants (Albano et al. 2009; Gibson et al. 2013; Ballantyne et al. 2015). If pollen from the invasive plant is deposited on the stigma of native flowers, pollination networks may be disrupted (Lopezaraiza-Mikel et al. 2007). Conspecific pollen loss on heterospecific flowers can decrease the volume of pollen conveyed between conspecific flowers (Morales and Traveset 2008; Jakobsson et al. 2008; Molina-Montenegro et al. 2008). Heterospecific pollen deposition on conspecific flowers or stigma can cause stigma clogging (Nielsen et al. 2008), thus reducing fruit and seed production. Jakobsson et al. (2008) found a reduced seed set of native Helichrysum stoechas as a result of clogging due to alien pollen from invasive Carpobrotus spp. Similarly, Nielsen et al. (2008) showed that invasive Heracleum mantegazzianum reduced the seed set of Mimulus guttatus via heterospecific pollination. Moreover, most invasive plants displace native plants via competition for resources and/or allelopathy besides competition for flower visitors (Nielsen et al. 2008; Kaiser-Bunbury and Müller 2009).

Parthenium hysterophorus is native to North and South America but introduced in Africa, Asia, Australia, and Oceania (Shabbir and Bajwa 2006; Kaur et al. 2014; Usharani and Raju 2018). In Africa, it has invaded many countries in sub-Saharan Africa (Wakjira et al. 2009). In Tanzania, P. hysterophorus has invaded agricultural fields and rangelands in Arusha, Kilimanjaro, Manyara and Kagera regions. Prompt germination, high fecundity, rapid growth and spread are traits that have facilitated its successful rapid invasion (Shabbir et al. 2013). Similar to other invasive plants, $P$. hysterophorus may have positive, negative or neutral effect on pollination of native plants because of competition for flower visitors (Gibson et al. 2013; Ballantyne et al. 2015; Usharani and Raju 2018). Because $P$. hysterophorus shares flower visitors with native flowering plants, we postulated that it can 
exert negative effects on native plants by attracting flower visitors away from the latter. Parthenium hysterophorus pollen contains allelopathic compounds (Kaur et al. 2014; Shrestha et al. 2015) which may additionally impact the flower visitors since most flower visitors have not had the time to co-evolve with the rapid invasion of $P$. hysterophorus. The allelopathic compounds expressed in pollen can damage the pollinator fitness as shown in other plant studies (Arnold et al. 2014; Tiedeken et al. 2015). While evidence about the negative impact of $P$. hysterophorus on crop productivity, diversity and composition of native plants through allelopathy (de Miranda et al. 2014) and competition for space, light, nutrients and water (Shabbir and Bajwa 2006; Shabbir et al. 2013; Shrestha et al. 2015) is accumulating, there remains a gap in knowledge about the impact of $P$. hysterophorus on pollination services for co-flowering plants. Also, the flower visitors and pollinator guild of $P$. hysterophorus have not been investigated. Therefore, the overall study questions were (i) what insect species visit $P$. hysterophorus and other co-flowering plants? (ii) does $P$. hysterophorus negatively affect neighbouring coflowering plants by competing for flower visitors? The two target plant species (native Ocimum gratissimum and introduced Ageratum conyzoides) commonly found in invaded areas were used to investigate the effect of $P$. hysterophorus by hypothesizing that (i) P. hysterophorus shares flower visitors with neighbouring co-flowering target plants, (ii) it reduces the number of arriving flower visitors and visitation rate to target plants, (iii) it decreases the duration of visits on target plants, and (iv) it integrates in the networks of plant-flower visitors. These hypotheses were tested by surveying the flower visitor insect species on ecologically similar sites with and without $P$. hysterophorus invasion and observing their flower visiting behaviour.

\section{Materials and Methods}

\section{Study plant species}

Parthenium hysterophorus is an annual herbaceous plant (1.0 - $1.2 \mathrm{~m}$ tall) with on average 810 small creamywhite flower heads per plant (Fig.1) (Kushwaha and Maurya 2012). These flowers produce abundant pollen of about 624 million grains per plant (Kaur et al. 2014). Its inflorescence is $0.5-1.5 \mathrm{~cm}$ in diameter, and corymb like (Kushwaha and Maurya 2012). In addition to benefiting from insect pollination the flowers are pollinated by wind. Ocimum gratissimum (Lamiaceae) and Ageratum conyzoides (Asteraceae) were used as target species to investigate the mediated impact of $P$. hysterophorus on flower visitation and foraging behaviour of flower visitors on neighbouring co-flowering plant species (Fig.1). O. gratissimum is an erect shrub growing 0.5 to $3.0 \mathrm{~m}$ tall (Nweze and Eze 2009) and native to East Africa. It has zygomorphic, nectar-rich inflorescences attracting flower visitors. A. conyzoides is an annual erect branched herb with 0.5 to $1.0 \mathrm{~m}$ height (Kohli et al. 2006). The branched inflorescence of A. conyzoides carries pale purple coloured flower heads which are arranged in flat-topped clusters. Although A. conyzoides is non-native to Tanzania, it was chosen because (i) it has morphologically similar flowers with $P$. hysterophorus, and (ii) like $O$. gratissimum it was abundant co-flowering plant with $P$. hysterophorus in field sites.

\section{"Figure 1 about here"}

\section{Field sites}

The field work was conducted at two sites invaded with P. hysterophorus, at Tengeru $\left(3^{\circ} 22.002^{\prime} \mathrm{S}, 36^{\circ} 47.008^{\prime}\right.$ E, 1387 m a.s.l) and Mikuuni-King’ori ( $3^{\circ} 20.613^{\prime} \mathrm{S}, 36^{\circ} 59.892^{\prime} \mathrm{E}, 1165.86 \mathrm{~m}$ a.s.l) in Meru district, Arusha region 
of Tanzania. The mean annual temperature in Tengeru and Mikuuni-King'ori is $19.5^{\circ} \mathrm{C}$ and $19.6^{\circ} \mathrm{C}$, and average annual rainfall is $1078 \mathrm{~mm}$ and $1361 \mathrm{~mm}$, respectively. Each site (ca. 4 ha) was situated within an agricultural landscape and relatively close $(<200 \mathrm{~m})$ to settlements. At each study site, two areas ca. $100 \mathrm{~m}$ apart, with and without $P$. hysterophorus invasion (invaded and uninvaded quadrats respectively) were selected for studying foraging behaviour, visitation of flowers and visitation networks. The two sites had similar soil type, vegetation type and coverage. Prior to observations uninvaded and invaded quadrats were assessed to ensure that the target co-flowering plant species were present.

\section{Visitation of flower visitors and experimental design}

Five permanent quadrats (plots) of $25 \mathrm{~m}^{2}$ were randomly established over co-flowering patches within invaded and uninvaded sites at Tengeru between January and April 2018 during P. hysterophorus flowering periods. Each quadrat was marked using a marker stick positioned at each corner of the quadrat. Prior to observations, the number of floral units of each target plant species within each $25 \mathrm{~m}^{2}$ quadrat was counted. The flower visitors were observed within quadrats over two days per week in each month. Each quadrat was observed twice per day, once in the morning (08:00 - 12:00) and once in the afternoon (14:00 - 18:00) for 15 minutes in the same order. The observer noted the number of arriving flower visitors and taxonomic groups in the quadrats. The time spent per flower on the target plant species by each visitor was recorded using a stop watch. Photographs and video clips of flower visitors were taken during field work to aid in identification. Every site was observed on the same day in the absence of rainfall and harsh winds that would affect the activity of flower visitors. Any flower insect visitor that touched the floral parts or reproductive parts of a flower (anthers or stigmas) of O. gratissimum, A. conyzoides, and $P$. hysterophorus during the 15 minute period was considered as a potential pollinator (Stiers et al. 2014; Ballantyne et al. 2015). However, the term flower visitor instead of pollinator is used in this text as it was not feasible to confirm whether every flower visitor was an effective pollinator. Visit in this study refers to landing of an insect visitor on a flower, which may include probing for nectar and/or pollen, which results in contact with the anthers or stigmas. Flower visitors were identified to taxonomic group level, using the categories: Hymenoptera (honey bees, other bees, wasps, and ants), Lepidoptera (brown veined white butterflies, acraea butterflies, monarch butterflies and other butterflies), Coleoptera (blister beetles, ladybird beetles, chafer beetles, and other beetles), Diptera (hoverflies, and other flies), and Hemiptera. Visitation rate was calculated according to Stiers et al. (2014) as the number of flower visitors to the individual target plant divided by the number of open flowers or inflorescences of that plant within the quadrat to avoid the bias of unequal flower numbers between replicates.

\section{Plant-flower visitor network analysis}

Considering the absence of studies on flower visitor guilds of $P$. hysterophorus and guilds of flower visitors shared with native flowers, we set out to map the interactions of flower visitors and flowering plants available in the study site. Five $36 \mathrm{~m}^{2}$ quadrats were randomly established in the invaded and uninvaded sites at Mikuuni and Tengeru. Twice a week from April to June 2018, quadrats were observed in the same order, in the morning (08:00 - 12:00) and afternoon (14:00 - 17:00) for 15 minutes while recording plant-flower visitor interactions. Since it was difficult to identify all flower visitors on P. hysterophorus and co-flowering plants to species level in the field, visitors were identified by eye where possible, some were photographed, and a representative subset were 
captured using a sweep net. These preserved specimens were then taken to the University of Dar-es-Salaam, Department of Zoology, for identification. A quantitative plant-flower insect visitor network or interaction for each site was constructed using R bipartite package 2.08 (Dormann et al. 2009) based on the number of visits by flower visitors to each plant species. Interaction networks are tools, which help to understand plant-flower visitor communities, and to investigate possible threats to plant diversity and food production if the ecosystem service (pollination) provided by pollinators decreases (Dormann et al. 2009; Ferrero et al. 2013; Ballantyne et al. 2015). The network-level metrics including connectance, nestedness, linkage density, links per species, and generality were calculated based on the number of visits by flower visitors to each plant species (Blüthgen et al. 2008; Dormann et al. 2009; Padrón et al. 2009; Ferrero et al. 2013; Ballantyne et al. 2015 ).

\section{Statistical data analysis}

The impact of $P$. hysterophorus on visitation (the number of arriving flower visitors and visitation rate) and foraging behaviour (duration of visits) on target native O. gratissimum and exotic A. conyzoides plants was analysed using one-way ANOVA (general linear model procedure) with the number of quadrats as the unit of replication and invasion status as categorical predictor. Flower visitor taxonomic groups were compared between the invaded and uninvaded quadrats. Homogeneity of variance and normality were tested using Levene's test and Shapiro-Wilk test respectively. When the parametric assumptions were not confirmed after transformations (Boxcox or log transformation), the non-parametric Kruskal-Wallis test was used. Significant differences were confirmed using the post-hoc Tukey-Kramer HSD and Mann-Whitney Pairwise comparison test. A 5\% significance level was used for all the tests. Statistical tests were performed with Origin version 9.0 SR1 (2013), while R version 3.5 .1 (2018) was used to construct pollinator visitation network and calculate network level metrics. Hemiptera were not compared between sites because their sample size was small, and therefore they were considered as minor flower visitors.

\section{Results}

\section{Flower visitor guild in invaded and uninvaded sites}

The flower visitors on P. hysterophorus, O. gratissimum, and A. conyzoides comprised a diversity of insect species (Table 1, and Fig.2). We recorded twice as many visits to flowers of O. gratissimum and A. conyzoides in the uninvaded quadrats compared to invaded quadrats (Table 2). In the invaded quadrats, $P$. hysterophorus received 1209 visits also about twice as many visits compared to the other two indicator plant species (Table 2). Hymenoptera and Diptera were the dominant taxa recorded with $>50 \%$ of all recorded visits (Table 2). Apis mellifera was the most frequent visitor to target species in both invaded and uninvaded quadrats as well as to flowers of both O. gratissimum (55\%) and A. conyzoides (50\%) in the uninvaded quadrats (Table 2). Apis mellifera also made about $55 \%$ of visits to flowers of $P$. hysterophorus compared to O. gratissimum and A. conyzoides in the invaded quadrats (Table 2).

\section{"Table 1 about here"}

"Figure 2 about here" 
"Table 2 about here"

\section{Flower visitor-mediated impact of $P$. hysterophorus}

The relative proportion of visits to $O$. gratissimum and A. conyzoides by different visitor taxa changed significantly in the presence of $P$. hysterophorus. Both target plants experienced a significant reduction in visits by Hymenoptera (A. mellifera, ants, and wasps), most beetles, butterflies, and flies on the invaded quadrats (Table 3). Post hoc tests revealed that the number of visits of A. mellifera to target plants was significantly higher on the uninvaded quadrats, about twice the number of visits on the invaded quadrats (O. gratissimum: $\mathrm{p}=0.0122 ; A$. conyzoides: $\mathrm{p}<0.0001$, Fig. 3a, b). The number of arriving blister beetles $(\mathrm{p}=0.0117)$, and ladybird beetles $(\mathrm{p}=$ 0.0157) to O. gratissimum (Fig. 3c), and ladybird beetles to A. conyzoides ( $\mathrm{p}=0.0013$, Fig. 3d) on the uninvaded quadrats was twice as high compared to that on the invaded quadrats. Similarly, the number of acraea butterflies visiting $O$. gratissimum ( $\mathrm{p}=0.0026$, Fig. 3e) and other butterflies visiting A. conyzoides $(\mathrm{p}=0.0283$, Fig. 3f) on the uninvaded quadrats was about twice the number of visits on the invaded quadrats. Moreover, the number of visits of hoverflies $(\mathrm{p}=0.0001)$, and other flies $(\mathrm{p}=0.0001)$ to flowers of $O$. gratissimum and other flies $(\mathrm{p}=$ 0.0013) to A. conyzoides on the uninvaded quadrats was about three times the number of visits on the invaded quadrats (Fig. 3g, h). Moreover, the number of arriving chafer beetles, monarch butterflies, ants, other bees, and wasps were not negatively affected by $P$. hysterophorus (Fig 3a-f).

"Table 3 about here"

"Figure 3 about here"

\section{Duration of visits and flower visitation rate in invaded and uninvaded sites}

Duration of visits and visitation rate of insect taxonomic groups, the bees, ants and wasps, beetles, butterflies, and flies to flowers of target plants was significant different between the invaded and uninvaded quadrats but not the visitation rate of butterflies and flies to flowers of $A$. conyzoides (Table 3). In general, insects spent longer time interacting with individual flowers of both target species on the uninvaded quadrats, the duration of visits of $A$. mellifera to flowers of $O$. gratissimum ( $\mathrm{p}=0.0216$, Fig. $4 \mathrm{a}$ ) and A. conyzoides $(\mathrm{p}=0.0122$, Fig. $4 \mathrm{~b})$ on the uninvaded quadrats was about two and three times the duration of visits on the invaded quadrats respectively. The duration of visits of ladybird beetles ( $p=0.0122$, Fig. $4 c$ ), other beetles $(p=0.0119$, Fig. $4 c)$, acraea butterflies $(\mathrm{p}=0.0117$, Fig. 4e), other butterflies $(\mathrm{p}=0.0022$, Fig. 4e), and hoverflies $(\mathrm{p}=0.0122$, Fig. $4 \mathrm{~g})$ to flowers of $O$. gratissimum on the uninvaded quadrats was about twice the duration of visits on the invaded quadrats. Also, other flies (O. gratissimum: $\mathrm{p}=0.0119$, Fig. 4g), ladybird beetles (A. conyzoides: $\mathrm{p}=0.0122$, Fig. $4 \mathrm{~d}$ ), and other butterflies (A. conyzoides: $\mathrm{p}=0.0122$, Fig. 4f) had longer duration of visits to flowers of target plants on the uninvaded quadrats, about three times the duration of visits on the invaded quadrats. Moreover, the duration of visits of blister beetles ( $p=0.0122$, Fig. $4 \mathrm{~d})$ and other flies $(\mathrm{p}=0.0122$, Fig. $4 \mathrm{~h})$ to flowers of A. conyzoides on the uninvaded quadrats was twice the duration of visits on the invaded quadrats, and that of hoverflies $(\mathrm{p}=0.0121$, Fig. 4h) on the uninvaded quadrats was four times the duration of visits on the invaded quadrats.

Furthermore, the visitation rate by A. mellifera to the flowers of O. gratissimum (p =0.0012, Fig. 5a) and A. conyzoides ( $\mathrm{p}=0.0001$, Fig. $5 \mathrm{~b}$ ) on the uninvaded quadrats was about twice the visitation rate of $A$. mellifera on the invaded quadrats. Also, the visitation rate of blister beetles $(p=0.0119$, Fig. $5 c)$, ladybird beetles $(p=0.0032$, 
Fig. 5c), and acraea butterflies ( $\mathrm{p}=0.0432$, Fig. 5e) to flowers of $O$. gratissimum, and lady beetles $(\mathrm{p}=0.0367$, Fig. 5d) to flowers of A. conyzoides on the uninvaded quadrats was about twice as high compared to that on the invaded quadrats. Moreover, the visitation of rate of hoverflies $(\mathrm{p}=0.0178$, Fig. $5 \mathrm{~g})$ to flowers of O. gratissimum on the uninvaded quadrats was three times the visitation rate on invaded quadrats. In contrast, the visitation rate of flies $(\mathrm{H}=6.91$, df =3, p > 0.05, Fig. 5h) and butterflies $(\mathrm{H}=16.13$, df $=7, \mathrm{p}<0.05$, Fig. 5f $)$ to flowers of $A$. conyzoides did not differ statistically between the invaded and uninvaded quadrats (Table 3 ).

\section{"Figure 4 about here"}

\section{"Figure 5 about here"}

\section{Visitation network of plant-flower visitors}

A total of 1103 and 987 interactions between co-flowering plant species and flower visiting-insects on the invaded sites, and 429 and 555 interactions on the uninvaded sites were recorded at Tengeru and Mikuuni, respectively. The mean number of interactions per site was similar between invaded and uninvaded sites (766 and 771 , respectively). $P$. hysterophorus interacted with $27 \%$ and $63 \%$ of co-flowering invasive and native plant species, respectively via the flower visitors. Plant species shared A. mellifera as the main flower visitor, which also was the most frequent visitor to $P$. hysterophorus in both sites with a total of $60 \%$ of visits. Flower visitors visited more than one plant species, however, no plant species seemed to be pushed out of the network in the invaded sites (Fig. 6). At taxonomic level, insect taxa did not differ significantly between the two sites. Although some taxa appeared to alter their visitation patterns subtly in the presence of $P$. hysterophorus - for instance, hoverflies seem to stop visiting other plants and mostly go to P. hysterophorus (Fig. 6). Network metrics were similar, regardless of whether the site was invaded or not (connectance, and specialisation, Table 4). However, nestedness was higher at both uninvaded sites compared to their corresponding invaded ones, indicating a higher level of randomness in the interactions on the uninvaded sites (Table 4). Generality and links per species are lower on the uninvaded sites as all insect groups showed more generalised behaviour on the invaded sites (interacting with a larger number of plants) (Table 4).

\section{"Figure 6 about here"}

"Table 4 about here"

\section{Discussion}

Parthenium hysterophorus is considered as superlative competitor that crowds out native plants via allelopathy and competition for nutrients, light, water and space (Witt et al. 2018). While this direct impact to native plants is known, our study highlighted its indirect impact to natives through interactions with insect flower visitors. We found that $P$. hysterophorus received visits from a diversity of different insect flower visitors, mainly Apis mellifera, Calliphoridae, Coccinellidae, Syrphidae, B. aurota, Melyridae, Meloidae, and Hemiptera. The invasive ray florets (female part), rich in nectar and pollen, in the capitulum acted as primary attractant of flower visitors (Usharani and Raju 2018) but the flowers have been previously observed as pollen-rich overall (Martins 2014). This enhanced the visitors' foraging activity on invasive flowers. Thus, the occurrence of P. hysterophorus significantly increased the number of potential pollinators, especially A. mellifera, in the invaded quadrats in our 
study. However, the presence of the invasive plant attracted these flower visitors away from other plants $(O$. gratissimum and A. conyzoides), which in the case of native plants implies the potential for a strong negative effect on wild plant reproductive success.

Flower visitors and potential pollinators to flowering plants are attracted by floral abundance (Ghazoul 2004; Lopezaraiza-Mikel et al. 2007) and floral morphology (McKinney and Goodell 2011). Generalised flowers with easy access to the nectar tend to attract a larger diversity of non-specialist visitors compared to flowers with specialised morphology such as long corollas or complex mechanisms (Johnson and Steiner 2000). Common to many Asteraceae, the non-tubular flowers of $P$. hysterophorus (Kaur et al. 2014; Usharani and Raju 2018) likely attract predominantly generalist flower visitors such as A. mellifera and Syrphidae (hoverflies). These generalists visited other wild plants in the area less frequently in the presence of $P$. hysterophorus, which agrees with many previous studies on invasive plants (Totland et al. 2006; Brown et al. 2002; Jakobsson et al. 2008; Sun et al. 2013). Our results are consistent with that of Stiers et al. (2014) which showed that invasive Ludwigia grandiflora, a plant with similarly generalised floral morphology and accessible nectar/pollen, can negatively impact on the number of arriving pollinators and visitation rate of native Lythrum salicaria, and Totland et al. (2006), who showed that presence of the invasive Phacelia tanacetifolia had strong negative effects on the visitation rate to the native Melampyrum pratense. A high visitation rate from effective pollinators enhances gene flow within plant populations, and contributes to community stability of native plants (Lopezaraiza-Mikel et al. 2007; Gibson et al. 2013; Albrecht et al. 2016). However, our findings that $P$. hysterophorus lowered flower visitor frequencies and visitation rates to wild plants indicates $P$. hysterophorus invasion may interrupt pollen flow between native plants in invaded ecosystems (Albano et al. 2009; Gibson et al. 2013; Sun et al. 2013) and significantly harm native plants' reproduction by reducing seed set (Chittka and Schürkens 2001; Albano et al. 2009; Stiers et al. 2014). The potential ecological damage of $P$. hysterophorus can affect more the diversity and density of rare or endangered species via multiple means (Brown et al. 2002; Jakobsson et al. 2008; Nielsen et al. 2008).

Our results also suggest that $P$. hysterophorus has the potential to disrupt native plant-pollinator networks, which can have wider-reaching impacts on abundance and diversity of native plants in a habitat (Totland et al. 2006; Lopezaraiza-Mikel et al. 2007; Morales and Traveset 2008; Gibson et al. 2013; Sun et al. 2013). While invasive plants sometimes integrate into the existing flower visitors' networks (Lopezaraiza-Mikel et al. 2007; Aizen et al. 2008; Padrón et al. 2009; Albrecht et al. 2014; Emer et al. 2015), they may disrupt the flow of native pollen through the networks within the recipient ecosystems ( Lopezaraiza-Mikel et al. 2007; Chittka and Schürkens 2001; Padrón et al. 2009; Albrecht et al. 2016). In our visitation networks, P. hysterophorus interacted with native and introduced co-flowering plants by sharing a wide range of insect flower visitors, some of whom are pollen vectors such as A. mellifera and Syrphidae. Apis mellifera played a significant role as an integrator of $P$. hysterophorus into flower visitor networks in our study (Padrón et al. 2009; Stiers et al. 2014; Barrios et al. 2016). This generalist flower visitor tended to visit diverse flowers of different plant species including $P$. hysterophorus. However, A. mellifera individuals show one of the highest levels of floral constancy of any pollinator (Chittka et al. 1999). We found high nestedness in the uninvaded sites which indicates the presence of more interactions and generalist dominance (Blüthgen et al. 2008), and higher stability of networks in these sites (Ballantyne et al. 2015). As $P$. hysterophorus is a generalist plant (species with many links) which receives both generalist and specialist 
flower visitors, it could push out specialist plants (species with few links) from the networks by attracting flower visitors away from these plants (Brown et al. 2002; Blüthgen et al. 2008). Low linkage density in invaded sites infers that $P$. hysterophorus decreases plant-insect flower visitor interactions in these sites (Padrón et al. 2009; Ferrero et al. 2013). Furthermore, its integration into networks reduced native plant-pollinator interactions and therefore lead to reduced robustness. The consequences of this could include the disruption of pollination networks, reduced native plant seed set, productivity, and community stability. However, in our field sites, $P$. hysterophorus did not show a large effect on the visitation network structure.

Since the invasive is faculatatively autogamous and anemophilous, it will set seed even without the presence of insect flower visitors (Usharani and Raju 2018). However, it may be drawing pollinators away from plants that need them more than this invasive species. Native plants reliant on pollinators to transport pollen between individuals are more prone to competition for pollination with $P$. hysterophorus than self-compatible plants able to carry out autonomous pollination (Brown et al. 2002; Nielsen et al. 2008). Thus, other plant species, in contrast, will not be able to survive without pollinators. As visitation rate and number of flower visitors to native coflowering plants are negatively affected in the presence of $P$. hysterophorus, thus, the invasive must be controlled to ameliorate negative impacts on native and established plant communities (Albrecht et al. 2016; Fantinato et al. 2018). Additionally, given other proven allelopathic effects of this species, it is possible that the pollen of $P$. hysterophorus may have traits to which co-flowering plants are not adapted, and may hinder fertilization due to stigma-clogging in native flowers (Chittka and Schürkens 2001; Nielsen et al. 2008; Flanagan et al. 2009; KaiserBunbury and Müller 2009). Such effects have been reported in other invasive species including Carpobrotus spp, Oxalis pes-caprae, Lythrum salicaria, and Heracleum mantegazzianum (Brown et al. 2002; Jakobsson et al. 2008; Nielsen et al. 2008; Albrecht et al. 2016). While A. mellifera and Syrphidae could conceivably be important pollinators of all three plant species, Melyridae, Meloidae, and Coccinellidae did not act as major flower visitors in our study and are seldom recorded as pollinators. Their visits are likely to be related to either feeding (for instance, on flowers but also on aphids) or mating behaviour (Shimamura et al. 2005). The shorter duration of visits by A. mellifera, Syrphidae, other Diptera and some Lepidoptera to flowers of $O$. gratissimum and $A$. conyzoides in invaded quadrats could be due to competition with P. hysterophorus. As many Coleoptera (Shimamura et al. 2005) and Diptera (Irvin et al. 1999) are pollen feeders, we anticipate these taxa were attracted to flowers of $P$. hysterophorus due to volume of pollen in our study. Moreover, in this study, the visitation rate of Diptera to flowers of A. conyzoides was not strongly affected by $P$. hysterophorus which could be due to their similar flower morphology or a stronger preference for A. conyzoides among this taxon, perhaps because of cues such as colour or odour.

Despite the effects of invasive plants being difficult to predict, our study shows that $P$. hysterophorus has potential to displace native plants via competition for pollinator visits. In our study, it exerted a magnet species effect on A. mellifera and Syrphidae (Molina-Montenegro et al. 2008; Gibson et al. 2013). However, the impacts could extended further as we do not know its long-term consequences on pollinator health and honey quality; other introduced plants with complex chemistry can have pollen or nectar compositions that are deleterious to some pollinator groups (Arnold et al. 2014; Tiedeken et al. 2015). By attracting flower visitors that could otherwise serve as pollinators of native plant species and crops, $P$. hysterophorus, which is rapidly spreading in eastern 
African ecosystems and crop fields (Witt et al. 2018), could have complex harmful effects on the wider ecosystem. As a relatively high number of generalist pollinators visit $P$. hysterophorus, it is expected to see high seed sets in its existing habitats and the potential to invade more areas by both vegetative and sexual reproduction. Its invasions in crop fields and natural habitats could reduce pollination to native flowering plants and crops, thereby threatening biodiversity, ecosystem services and farmers' livelihoods. Since the invasive continues to spread in Tanzanian habitats, there is potential for it to exert more effects on a wider range of native species.

\section{Conclusion}

Parthenium hysterophorus appears to be attractive to flower visitors particularly generalists, and shares flower visitors with other co-flowering plants in Northern Tanzanian semi-natural grassland/scrubland habitat. It has integrated into the plant-pollinator network on sites where it has established, and competes for pollinators with co-flowering plant species, both native and introduced. With its increasing invasion, more studies are required to investigate the impact of $P$. hysterophorus on seed set and development of co-flowering natives, and whether flower visitors transfer alien pollen of $P$. hysterophorus to native flowering species. Moreover, as the plant has complex defensive chemistry (and induces allergic responses in some humans), its adverse effects on wild and managed pollinators, including A. mellifera, their brood, honey, and other hive products, should be investigated. Similarly, its allelopathic effects on wild plants' seed sets and pollinator activity should be studied. Both the wild plants and $P$. hysterophorus were visited by a diverse group of flower visitors. The impact of $P$. hysterophorus on visitation rates by flower visitors such as Melyridae, Meloidae, and Coccinellidae may not be important while its effect on potential pollinators such as Apidae and Syrphidae is. This study therefore recommends that eradication and/or management of $P$. hysterophorus is vital to ensure native plants' productivity and community stability. Furthermore, our results contribute to a growing literature showing that invasive-pollinator interactions can significantly affect pollinator visitation behaviour in a recipient ecosystem. Thus, $P$. hysterophorus, which was previously known to exert competitive effects on native plants via allelopathy, has been shown to do so also through competition for flower visitors.

\section{Acknowledgements}

Much appreciation is expressed to Dr Bruno Nyundo and Mr Emmanuel Mboya for helping in identification of insects and plants respectively, and Mr. Shabani Juma, Mr. Godson Mbise, Mr. Baraka Athuman, and Mr. Michael Joseph for facilitating field activities.

\section{Conflict of interests}

We declare that there is no conflict of interests. All of the authors agree to submission of this paper.

\section{Role of the funding source}

The study was financed by the World Bank through its African Centre of Excellence, "Centre for Research, agricultural Advancement, Teaching Excellence and Sustainability in Food and Nutritional Security (CREATES)", in the School of Life Sciences and Bioengineering at the Nelson Mandela Institution of Science and Technology (NM - AIST) in Arusha, Tanzania. We also received research equipment from the Idea Wild Foundation in the USA. 


\section{References}

Aizen MA, Morales CL, Morales JM (2008) Invasive mutualists erode native pollination webs. PLoS Biology 6:e31. doi: 10.1371/journal.pbio.0060031

Albano S, Salvado E, Borges PA, Mexia A (2009) Floral visitors, their frequency, activity rate and Index of Visitation Rate in the strawberry fields of Ribatejo, Portugal: selection of potential pollinators. Part 1. Advances in Horticultural Science 238-245

Albrecht M, Padron B, Bartomeus I, Traveset A (2014) Consequences of plant invasions on compartmentalization and species' roles in plant-pollinator networks. Proceedings of the Royal Society B: Biological Sciences 281:20140773-20140773. doi: 10.1098/rspb.2014.0773

Albrecht M, Ramis MR, Traveset A (2016) Pollinator-mediated impacts of alien invasive plants on the pollination of native plants: the role of spatial scale and distinct behaviour among pollinator guilds. Biological Invasions 18:1801-1812. doi: 10.1007/s10530-016-1121-6

Arnold SEJ, Idrovo MEP, Arias LJL, et al (2014) Herbivore defence compounds occur in pollen and reduce Bumblebee colony fitness. Journal of Chemical Ecology 40:878-881. doi: 10.1007/s10886-014-0467-4

Ballantyne G, Baldock KCR, Willmer PG (2015) Constructing more informative plant-pollinator networks: visitation and pollen deposition networks in a heathland plant community. Proceedings of the Royal Society B: Biological Sciences 282:20151130. doi: 10.1098/rspb.2015.1130

Barrios B, Pena SR, Salas A, Koptur S (2016) Butterflies visit more frequently, but bees are better pollinators: the importance of mouthpart dimensions in effective pollen removal and deposition. AoB Plants 8:plw001. doi: 10.1093/aobpla/plw001

Bjerknes A-L, Totland $\varnothing$, Hegland SJ, Nielsen A (2007) Do alien plant invasions really affect pollination success in native plant species? Biological Conservation 138:1-12. doi: 10.1016/j.biocon.2007.04.015

Blüthgen N, Fründ J, Vázquez DP, Menzel F (2008) What do interaction network metrics tell us about specialization and biological traits. Ecology 89:3387-3399. doi: 10.1890/07-2121.1

Brown BJ, Mitchell RJ, Graham SA (2002) Competition for pollination between an invasive species (Purple Loosestrife) and a native congener. Ecology 83:2328. doi: 10.2307/3072063

Chittka L, Thomson JD, Waser NM (1999) Flower constancy, insect psychology, and plant evolution. Naturwissenschaften 86:361-377. doi: 10.1007/s001140050636

Chittka L, and Schürkens S (2001) Successful invasion of a floral market-An exotic Asian plant has moved in on Europe's river-banks by bribing pollinators. Nature 411-653: 
Dormann CF, Frund J, Bluthgen N, Gruber B (2009) Indices, graphs and null models: analyzing bipartite ecological networks. The Open Ecology Journal 2:7-24. doi: 10.2174/1874213000902010007

Emer C, Vaughan IP, Hiscock S, Memmott J (2015) The impact of the invasive alien plant, Impatiens glandulifera, on pollen transfer networks. PLOS ONE 10:e0143532. doi: 10.1371/journal.pone.0143532

Engel EC, Irwin RE (2003) Linking pollinator visitation rate and pollen receipt. American Journal of Botany 90:1612-1618

Fang Q, Huang S-Q (2013) A directed network analysis of heterospecific pollen transfer in a biodiverse community. Ecology 94:1176-1185. doi: 10.1890/12-1634.1

Fantinato E, Del Vecchio S, Gaetan C, Buffa G (2018) The resilience of pollination interactions: importance of temporal phases. Journal of Plant Ecology. doi: 10.1093/jpe/rty005

Ferrero V, Castro S, Costa J, et al (2013) Effect of invader removal: pollinators stay but some native plants miss their new friend. Biological Invasions 15:2347-2358. doi: 10.1007/s10530-013-0457-4

Flanagan RJ, Mitchell RJ, Knutowski D, Karron JD (2009) Interspecific pollinator movements reduce pollen deposition and seed production in Mimulus ringens (Phrymaceae). American Journal of Botany 96:809815. doi: doi:10.3732/ajb.0800317

Ghazoul J (2004) Alien Abduction: Disruption of native plant-pollinator interactions by invasive species. Biotropica 156-164:9

Gibson MR, Pauw A, Richardson DM (2013) Decreased insect visitation to a native species caused by an invasive tree in the Cape Floristic Region. Biological Conservation 157:196-203. doi: 10.1016/j.biocon.2012.07.011

Irvin NA, Wratten SD, Frampton CM, et al (1999) The phenology and pollen feeding of three hover fly (Diptera: Syrphidae) species in Canterbury, New Zealand. New Zealand Journal of Zoology 26:105-115. doi: $10.1080 / 03014223.1999 .9518182$

Jakobsson A, Padrón B, Traveset A (2008) Pollen transfer from invasive Carpobrotus spp. to natives - A study of pollinator behaviour and reproduction success. Biological Conservation 141:136-145. doi: 10.1016/j.biocon.2007.09.005

Johnson SD, Steiner KE (2000) Generalization versus specialization in plant pollination systems. Trends in Ecology and Evolution 15:140-143. doi: 10.1016/S0169-5347(99)01811-X

Kaiser-Bunbury CN, Müller CB (2009) Indirect interactions between invasive and native plants via pollinators. Naturwissenschaften 96:339-346. doi: 10.1007/s00114-008-0481-X 
Kaur M, Aggarwal NK, Kumar V, Dhiman R (2014) Effects and management of Parthenium hysterophorus: A Weed of Global Significance. 2014:1-12. doi: 10.1155/2014/368647

Kushwaha VB, Maurya S (2012) Biological utilities of Parthenium hysterophorus. Journal of Applied and Natural Science 4:137-143

Larson DL, Royer RA, Royer MR (2006) Insect visitation and pollen deposition in an invaded prairie plant community. Biological Conservation 130:148-159. doi: 10.1016/j.biocon.2005.12.009

Lázaro A, Jakobsson A, Totland Ø (2013) How do pollinator visitation rate and seed set relate to species? floral traits and community context? Oecologia 173:881-893. doi: 10.1007/s00442-013-2652-5

Lopezaraiza-Mikel ME, Hayes RB, Whalley MR, Memmott J (2007) The impact of an alien plant on a native plant-pollinator network: an experimental approach. Ecology Letters 10:539-550. doi: 10.1111/j.14610248.2007.01055.x

Martins D (2014) Our friends the pollinators: a handbook of pollinator diversity and conservation in East Africa. The East Africa Natural History Society, Nairobi, Kenya

McKinney AM, Goodell K (2011) Plant-pollinator interactions between an invasive and native plant vary between sites with different flowering phenology. Plant Ecology 212:1025-1035. doi: 10.1007/s11258-010-9882y

Molina-Montenegro MA, Badano EI, Cavieres LA (2008) Positive interactions among plant species for pollinator service: assessing the 'magnet species' concept with invasive species. Oikos 117:1833-1839. doi: 10.1111/j.0030-1299.2008.16896.x

Moragues E, Traveset A (2005) Effect of spp. on the pollination success of native plant species of the Balearic Islands. Biological Conservation 122:611-619. doi: 10.1016/j.biocon.2004.09.015

Morales CL, Traveset A (2008) Interspecific pollen transfer: magnitude, prevalence and consequences for plant fitness. Critical Reviews in Plant Sciences 7:221 — 238. doi: DOI: 10.1080/07352680802205631

Nielsen C, Heimes C, Kollmann J (2008) Little evidence for negative effects of an invasive alien plant on pollinator services. Biological Invasions 10:1353-1363. doi: 10.1007/s10530-007-9210-1

Nweze EI, Eze EE (2009) Justification for the use of Ocimum gratissimum L in herbal medicine and its interaction with disc antibiotics. BMC Complementary and Alternative Medicine 9:. doi: 10.1186/1472-6882-9-37

Padrón B, Traveset A, Biedenweg T, et al (2009) Impact of alien plant invaders on pollination networks in two archipelagos. PLoS ONE 4:e6275. doi: 10.1371/journal.pone.0006275

R Core Team (2018) R: a language and environment for statistical computing. Center for statistics, Copenhagen Denmark: R foundation for statistical computing http://www.R-project.org 
S. F. de Miranda CA, G. Cardoso M das, M. de Carvalho ML, et al (2014) Chemical composition and allelopathic activity of Parthenium hysterophorus and Ambrosia polystachya weeds essential oils. American Journal of Plant Sciences 05:1248-1257. doi: 10.4236/ajps.2014.59137

Shabbir A, Bajwa R (2006) Distribution of parthenium weed (Parthenium hysterophorus L.), an alien invasive weed species threatening the biodiversity of Islamabad. Weed Biology and Management 6:89-95. doi: 10.1111/j.1445-6664.2006.00202.x

Shabbir A, Dhileepan K, O’Donnell C, Adkins SW (2013) Complementing biological control with plant suppression: Implications for improved management of parthenium weed (Parthenium hysterophorus L.). Biological Control 64:270-275. doi: 10.1016/j.biocontrol.2012.11.014

Shimamura R, Kachi N, Kudoh H, Whigham DF (2005) Visitation of a specialist pollen feeder Althaeus hibisci Olivier (Coleoptera: Bruchidae) to flowers of Hibiscus moscheutos L. (Malvaceae) ${ }^{1}$. The Journal of the Torrey Botanical Society 132:197-203.

Shrestha BB, Shabbir A, Adkins SW (2015) Parthenium hysterophorus in Nepal: a review of its weed status and possibilities for management. Weed Research 55:132-144. doi: 10.1111/wre.12133

Stiers I, Coussement K, Triest L (2014) The invasive aquatic plant Ludwigia grandiflora affects pollinator visitants to a native plant at high abundances. Aquatic Invasions 9:357-367. doi: 10.3391/ai.2014.9.3.10

Sun S-G, Montgomery BR, Li B (2013) Contrasting effects of plant invasion on pollination of two native species with similar morphologies. Biological Invasions 15:2165-2177. doi: 10.1007/s10530-013-0440-0

Tiedeken EJ, Egan PA, Stevenson PC, et al (2015) Nectar chemistry modulates the impact of an invasive plant on native pollinators. Functional Ecology 30:885-893. doi: 10.1111/1365-2435.12588

Totland O, Nielsen A, Bjerknes A-L, Ohlson M (2006) Effects of an exotic plant and habitat disturbance on pollinator visitation and reproduction in a boreal forest herb. American Journal of Botany 93:868-873. doi: 10.3732/ajb.93.6.868

Traveset A, Richardson DM (2014) Mutualistic interactions and biological invasions. Annual Review of Ecology, Evolution, and Systematics 45:89-113. doi: doi.org/10.1146/annurev-ecolsys-120213-091857

Usharani B, Raju AJS (2018) Reproductive ecology of the globally invasive whitetop weed. Phytologia balcanica $24: 225-238$

Wakjira M, Berecha G, Tulu S (2009) Allelopathic effects of an invasive alien weed Parthenium hysterophorus L. compost on lettuce germination and growth. African Journal of Agricultural Research 4:1325-1330

Weissman J, Schaefer H (2017) The importance of generalist pollinator complexes for endangered island endemic plants. Life and Marine Sciences 23-40:19 
Witt A, Beale T, van Wilgen BW (2018) An assessment of the distribution and potential ecological impacts of invasive alien plant species in eastern Africa. Transactions of the Royal Society of South Africa 73:217236. doi: 10.1080/0035919X.2018.1529003

Ye Z-M, Dai W-K, Jin X-F, et al (2014) Competition and facilitation among plants for pollination: can pollinator abundance shift the plant-plant interactions? Plant Ecology 215:3-13. doi: 10.1007/s11258-013-0274-y 